05

\title{
Диагностика разрушения армированного бетона в условиях изгиба по параметрам электрического отклика на ударное воздействие
}

\author{
(C) Т.В. Фурса, ${ }^{1}$ Д.Д. Данн, ${ }^{1}$ М.В. Петров, ${ }^{1}$ А.Н. Соколовский ${ }^{2}$ \\ ${ }^{1}$ Национальный исследовательский Томский политехнический университет, \\ 634050 Томск, Россия \\ ${ }^{2}$ University of Washington, Seattle, Department of Materials Science and Engineering, \\ Seattle, United States \\ e-mail: fursa@tpu.ru
}

(Поступило в Редакцию 1 марта 2018 г.)

Исследованы закономерности изменения напряженно-деформированного состояния армированного бетона в процессе испытания на четырехточечный изгиб. Проанализировано изменение характеристик электрического отклика на ударное воздействие в процессе последовательного увеличения внешней нагрузки. Выявлены закономерности связи параметров электрического отклика на ударное воздействие с этапами напряженнодеформированного состояния армированных балок в процессе изгиба. Предложены критерии определения стадий разрушения армированных балок по параметрам электрического отклика.

DOI: $10.21883 / J T F .2019 .01 .46969 .91-18$

\section{Введение}

Разрушение материалов на основе цемента является очень важным вопросом, так как структурная целостность инженерных сооружений имеет большое значение для обеспечения безопасности как инфраструктуры, так и людей. По объему использования в различных областях строительства железобетон находится на одном из первых мест. Это определяется, прежде всего, его сравнительной дешевизной и долговечностью. Долговечность железобетонной конструкции зависит от коррозии, возникающей под воздействием внешней агрессивной среды. В результате этого происходит потеря несущей способности железобетонных конструкций и в целом зданий и сооружений. Композиционная полимерная арматура все чаще используется в качестве альтернативы стали, благодаря ее электромагнитной прозрачности, более высокой стойкости к коррозии в агрессивных средах и высокому соотношению прочности к весу, по сравнению со стальной арматурой [1]. Конструкции из армированного бетона часто эксплуатируются в условиях изгиба. Поэтому поведение бетонных балок в условиях изгиба широко изучается в литературе. Исследуются деформации и напряжения в бетонных балках, изучаются модели изгибных трещин, исследуется нагрузочно-деформационное поведение и процессы трещинообразования в условиях изгиба $[2,3]$. Поведение бетонных армированных балок в условиях изгиба в значительной степени зависит от прочности связи арматуры с бетоном. Поведение связи широко проанализировано при краткосрочном тестировании армированного бетона в процедуре выдвижных испытаний [4]. В процессе длительной эксплуатации в естественных условиях конструкций из армированного бетона происходит их постепенное разрушение. Поэтому существует необходимость разработки методов контроля с целью обеспечения безопасной эксплуатации инженерных кон- струкций. В любой системе оценки и мониторинга жизненно важно использовать неразрушающий контроль, который является надежным и предоставляет информацию о реальном состоянии структуры. В настоящее время предложено большое количество методов, которые позволяют определять повреждения в бетоне. Среди них метод акустической эмиссии $[5,6]$, электрической и электромагнитной эмиссии [7-9], импакт-эхо методы $[10,11]$, ультразвуковые и лазерные методы [12-15], импедансные методы $[16,17]$ и др. Наряду с этими методами разрабатывается метод оценки повреждения бетона, основанный на характеристиках электрического отклика, возникающего в бетоне в результате импульсного механического воздействия [18-21].

Суть метода состоит в том, что объект исследования подвергается слабому ударному воздействию, в результате чего в образце начинают распространяться акустические волны, которые приводят к появлению переменного электрического поля. Электрическое поле является следствием деформации и смещения упругой волной двойных электрических слоев, расположенных на границах компонентов в бетоне и поляризации пьезокварца, который содержится в песке и гравии. Электрический измерительный приемник располагается в непосредственной близости от образца и находится в зоне действия этого поля. Проведенными ранее исследованиями установлено, что основной вклад в электрический отклик на ударное воздействие бетона вносит составляющая, связанная с пьезоэлектрическим эффектом при деформации пьезоэлектрических включений [18]. Разработанная на основе классических соотношений электродинамики и механики сплошных сред физико-математическая модель устанавливает однозначную связь между параметрами акустических волн, формирующихся в материале при ударном воздействии и характеристиками электрического отклика [20]. Поэтому параметры электрического отклика связаны с характе- 


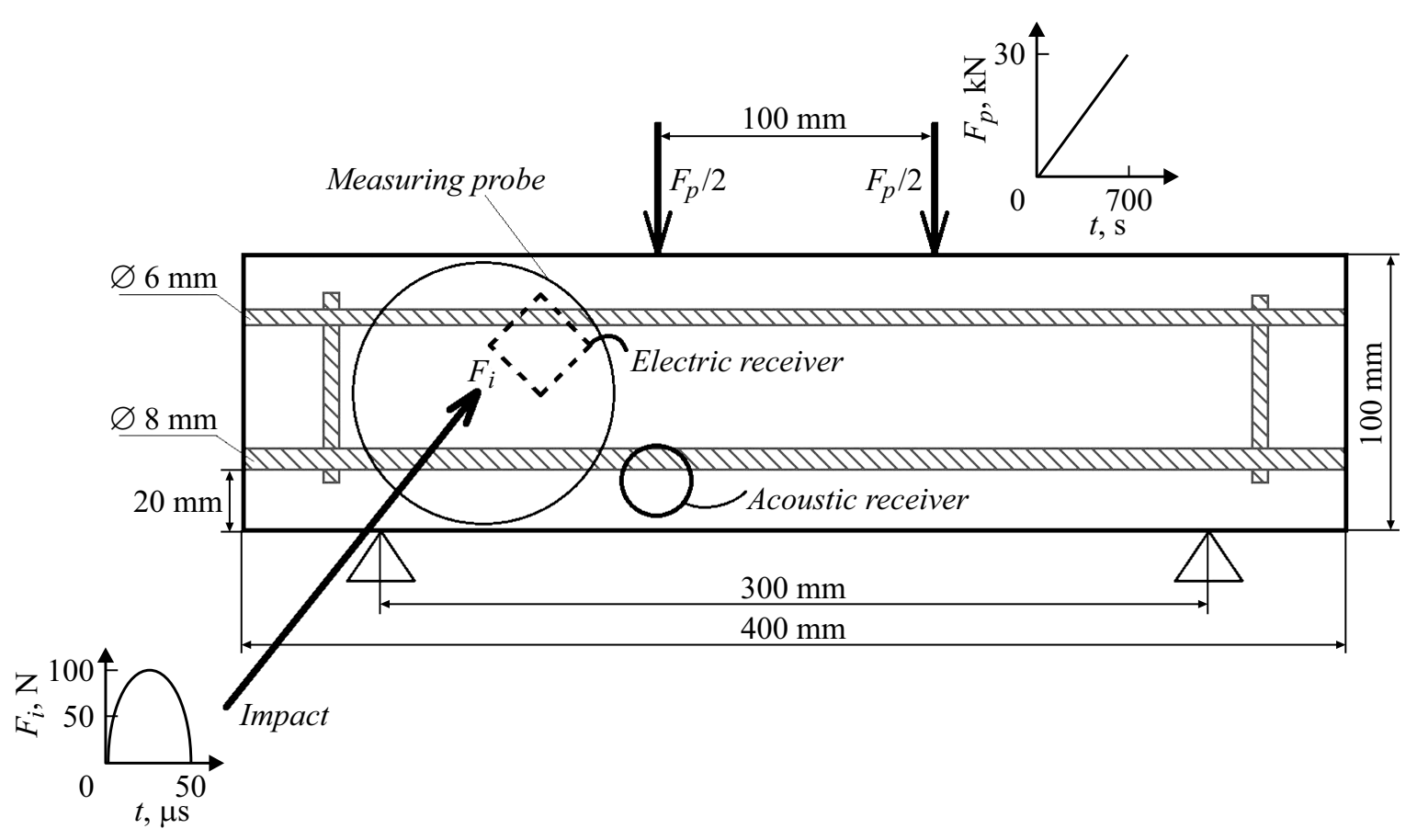

Рис. 1. Схема испытания армированных бетонных балок на изгиб.

ристиками упругих волн и надежно отражают процессы их взаимодействия с внутренними структурными неоднородностями и дефектами. Основным преимуществом предлагаемого в настоящей работе способа является то, что электрический отклик чувствителен к волнам, распространяющимся во всех направлениях в образце. Это связано с тем, что электрические оси пьезоэлектрических включений имеют различное направление. В результате этого предлагаемый метод чувствителен к дефектам при их различной ориентации и конфигурации.

Целью исследований приведенных в настоящей работе являлось изучение закономерностей изменения параметров электрического отклика на ударное воздействие армированных бетонных балок в процессе изгиба и поиск диагностических критериев оценки динамики их разрушения.

\section{1. Методика экспериментальных исследований}

Проведены экспериментальные исследования параметров электрического отклика на ударное воздействие образцов армированного бетона в условиях изгиба.

Для проведения исследований были изготовлены балки бетона размером $100 \times 100 \times 400 \mathrm{~mm}$, содержащие арматурный каркас. Арматурный каркас состоял из двух стальных или стеклопластиковых арматурных стержней диаметрами 6 и $8 \mathrm{~mm}$ длиной $400 \mathrm{~mm}$, которые были соединены между собой перемычками. Была использована стальная и стеклопластиковая арматура периодического профиля. Изготовление образцов бетона производилось согласно ГОСТ 7473-2010. Соотношение цемент/песок/крупный заполнитель было $1: 2: 4$ с максимальным размером заполнителя $20 \mathrm{~mm}$. Водноцементное отношение было 0.5 .

Были проведены исследования армированных бетонных балок в условиях комплексного квазистатического нагружения на четырехточечный изгиб с постоянной скоростью и периодического слабого ударного воздействия. Испытание на изгиб проводилось с использованием компьютеризированного пресса ИП-500. Расстояние между нижними и верхними опорами для проведения четырехточечного изгиба задавалось ГОСТ 10180-2012 и ASTMC78/C78M. Скорость нагружения составляла $0.05 \mathrm{kN} / \mathrm{s}$. Измерение нагрузки производилось датчиком давления Korund DI-120, а смещение с помощью датчика STTLX0050 Matest. B процессе нагружения c помощью специальной программы производилась регистрация нагрузки и смещения с дискретом по времени, равным 1s. В процессе квазистатического изгиба с постоянной скоростью с начала загрузки до разрушения проводилось дополнительное периодическое (через каждые 5-10s) слабое ударное воздействие вдоль боковой поверхности образца и измерялся электрический отклик на это воздействие. Для регистрации электрического отклика был использован аппаратно-программный комплекс, позволяющий производить импульсное ударное воздействие по образцу и регистрацию электрического отклика. Комплекс состоит из выносного измерительного зонда, источника питания, платы ввода-вывода и компьютера. Выносной зонд представляет собой металлический стакан, внутри которого расположено ударное устройство и дифференциальный электрический датчик. 

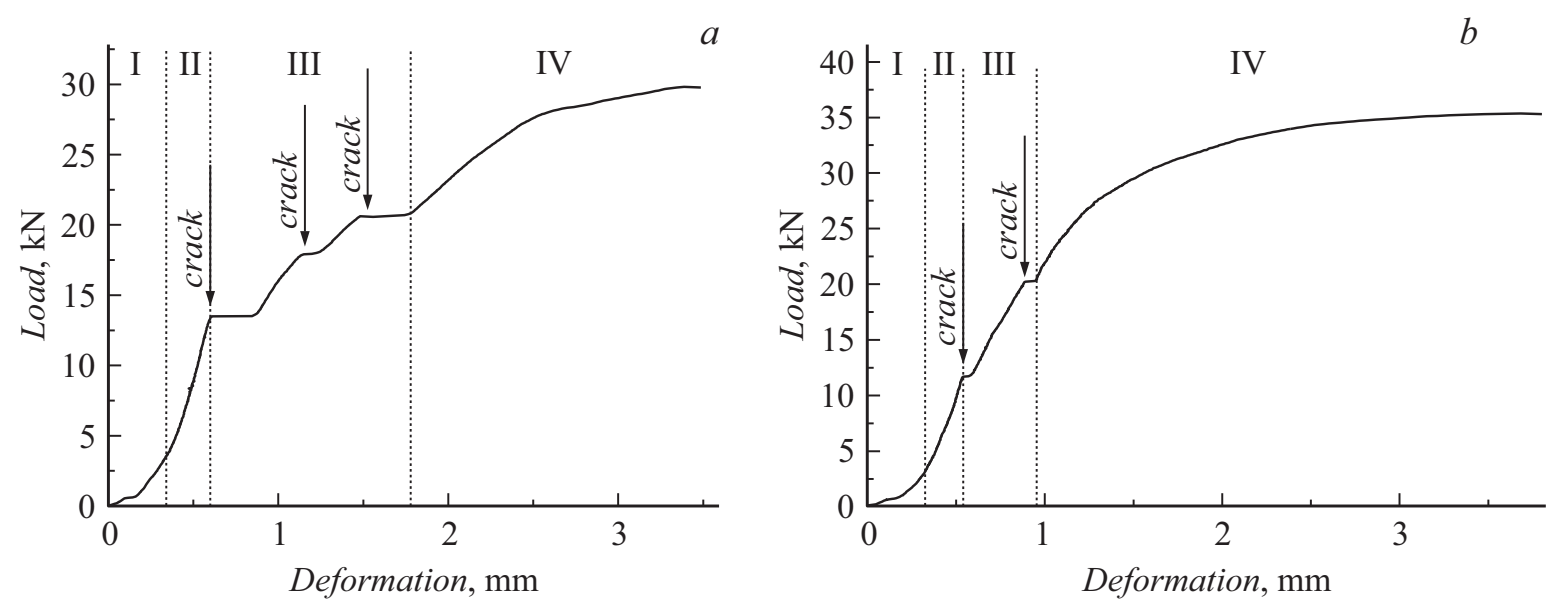

Рис. 2. Нагрузочные кривые при изгибе: $a-$ бетона, армированного стеклопластиковой и $b-$ стальной арматурой.

Ударное воздействие осуществляется с помощью электромеханического ударного устройства с нормированной силой удара $(100 \mathrm{~N})$ и длительностью $50 \mu$ s. Регистрация электрического сигнала производится с помощью дифференциального емкостного датчика, который позволяет значительно повысить соотношение сигналпомеха. Приемник дифференциального датчика состоит из измерительного электрода, размещенного на высоте $2 \mathrm{~mm}$ от поверхности образца, и компенсационного электрода, который находится на высоте $25 \mathrm{~mm}$ выше от измерительного электрода. Более подробно конструкция, достоинства дифференциального датчика и методика измерения электрического отклика на ударное воздействие изложены в работе [19].

Для проведения измерений электрического отклика в условиях изгиба измерительный зонд с помощью резиновых жгутов прикреплялся к боковой поверхности образца в зоне между верхним и нижним роллерами. Затем образец бетона вместе с зондом устанавливался на нижние роликовые опоры. На рис. 1 приведена схема эксперимента.

Нагружение производилось вплоть до момента, когда возникало резкое падение нагрузки на $10 \mathrm{kN}$. Для этого в управляющей программе задавалось максимальное снижение нагрузки, при котором происходила автоматическая остановка пресса.

Для обработки полученных данных используются стандартная программа Origin и специальные программы, разработанные в среде программирования LabVIEW.

\section{2. Экспериментальные результаты}

\section{1. Анализ напряженно-деформированного состояния армированного бетона при изгибе}

В процессе изгиба в армированной бетонной балке возникают внутренние механические напряжения, которые в различных областях могут достигать прочности на разрыв, и начинается процесс разрушения. Основная часть дефектов вызвана действием на армированную балку изгибающих моментов. Следовательно, характер разрушения армированной балки целесообразнее исследовать в процессе изгиба.

Проведены экспериментальные исследования характера трансформации упругопластических характеристик бетонных балок с различным видом арматуры в условиях испытания на изгиб. В процессе испытания производилось нагружение образцов армированного бетона на изгиб вплоть до момента, когда падение нагрузки составляло $10 \mathrm{kN}$, но не происходило полной потери целостности образцов. На рис. 2 приведены экспериментальные нагрузочные кривые при изгибных испытаниях бетонных балок.

Нагрузочные кривые при изгибе армированных балок имеют четыре характерных участка. Начальный криволинейный участок I от 0 до $3.5 \mathrm{kN}$ связан с разрушением более слабого поверхностного слоя бетона в зонах контакта с нижними и верхними роллерами. Затем идет участок линейной упругой деформации бетона II. Затем наступает этап появления трещин в нижнем слое бетона - зоне растяжения III. При нагрузках $12-14 \mathrm{kN}$ на нагрузочных кривых наблюдаются участки возрастания деформации без изменения нагрузки, связанные с возникновением трещин. Так как испытание на изгиб производилось с постоянной скоростью нагружения, то не происходило уменьшения нагрузки в момент прорастания трещины за счет обратной связи. В результате этого на нагрузочной кривой появляются полочки. Так как пластиковая арматура имеет меньший модуль упругости, то при одинаковой внешней нагрузке ее деформация значительно больше и на нагрузочной кривой более ярко видны участки возникновения или скачкообразного прорастания трещин. Как видно из рис. 2, при нагрузке выше $20 \mathrm{kN}$ нагрузочная кривая переходит в область нелинейных деформаций IV. На этом этапе, наряду с нарушением зоны контакта арматуры с бетоном, протекают процессы разрушения бетона в сжатой зоне. Как 

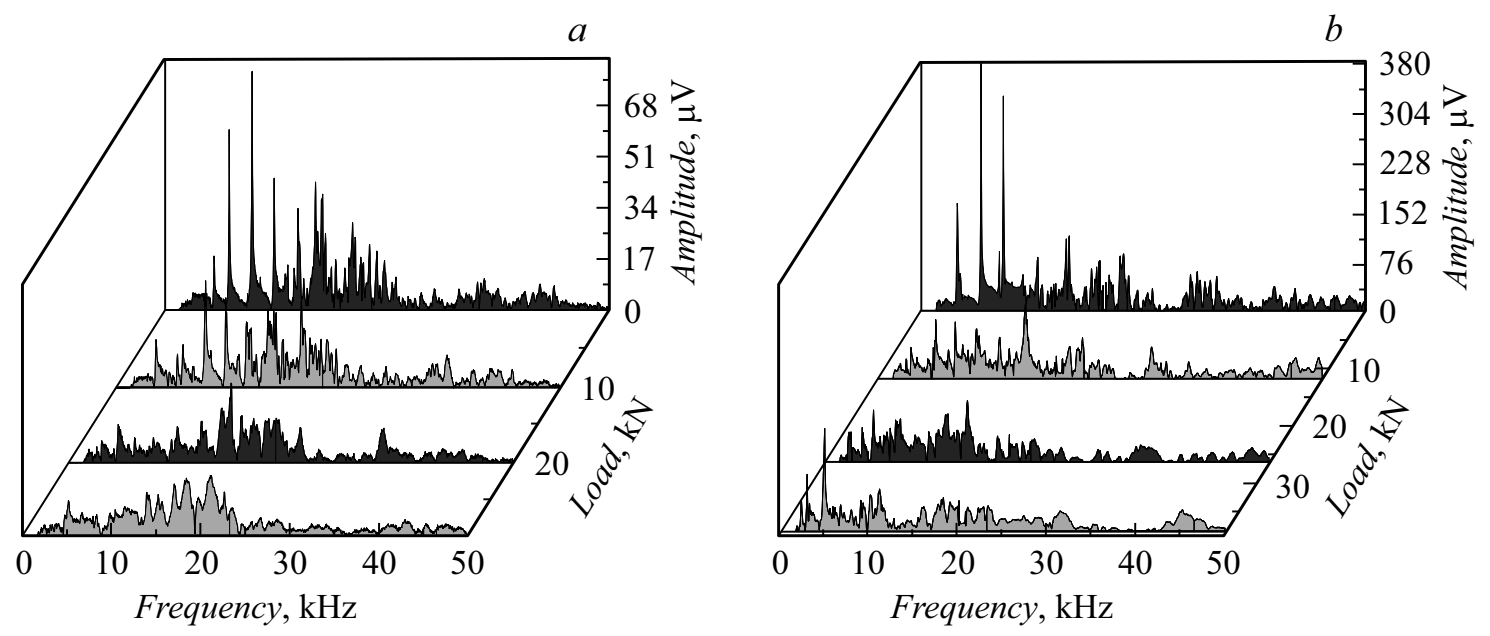

Рис. 3. Изменение амплитудно-частотных характеристик электрических откликов из бетонных балок, армированных стеклопластиковой $(a)$ и стальной $(b)$ арматурами в процессе изгиба.

видно из рис. 2, зоны III и IV имеют различия для бетона, армированного стальной и стеклопластиковой арматурой. В зоне трещинообразования III деформация балки, армированной стеклопластиковой арматурой, составляет порядка $1.1 \mathrm{~mm}$, а деформация балки, армированной стальной арматурой, порядка $0.5 \mathrm{~mm}$. Отличия в разрушении бетона, армированного стальной и стеклопластиковой арматурой, заключаются в том, что после образования трещин пластиковая арматура за счет меньшего модуля упругости прогибается сильнее. Размер микро- и макротрещин при одинаковой нагрузке в бетоне с металлической арматурой меньше, чем в бетоне со стеклопластиковой арматурой. В результате этого максимальная нагрузка, которую выдерживают образцы со стальной арматурой, выше, чем для образцов с пластиковой арматурой.

Установленные особенности в характере разрушения бетонных балок с различным типом арматуры должны найти свое отражение в параметрах электрического отклика, зарегистрированного на различных этапах изгибных испытаний.

\section{2. Поиск диагностических критериев оценки разрушения армированного бетона в условиях изгиба}

Для выявления диагностических критериев проведено всестороннее исследование ряда параметров электрического отклика на упругое ударное воздействие, и установлены основные закономерности их изменения в условиях разрушения армированных бетонных балок в условиях четырехточечного изгиба.

Механические напряжения, возникающие под действием внешней нагрузки, приводят к развитию трещин в бетоне. На разных этапах изгибных испытаний формируются трещины различных размеров и ориентации. C увеличением внешней механической нагрузки происходит увеличение размера и концентрации трещин в различных нарушенных зонах образца. Акустические волны, формирующиеся в образце в результате ударного воздействия, взаимодействуют с трещинами. При взаимодействии с трещинами происходит отражение акустических волн от трещин и их распространение вокруг трещин, что приводит при многократном прохождении фронта акустического возбуждения через образец к формированию в дефектном образце колебаний различных периодов. Наличие колебаний, имеющих различный период, отслеживает спектральная характеристика сигнала, полученная с помощью фурье-преобразования.

На рис. 3. приведены типичные спектры электрических сигналов из армированных бетонных балок в процессе их изгиба Из рис. 3 видно, что в процессе последовательного увеличения нагрузки в процессе изгиба наблюдается уменьшение амплитуды большинства спектральных пиков электрических откликов. Кроме того, в процессе разрушения происходит значительное уменьшение доминирующих пиков, в результате чего в спектрах сигналов наблюдается большое количество практически равнозначных спектральных пиков. Полученные результаты свидетельствуют о том, что амплитудно-частотные характеристики несут информацию о процессах разрушения армированного бетона в условиях изгиба.

Для количественной оценки изменения формы амплитудно-частотных характеристик электрических сигналов был использован корреляционный анализ. C помощью программы в среде программирования LabVIEW осуществлялось последовательное смещение спектров сигналов, зарегистрированных на различных этапах нагружения со спектром сигнала, зарегистрированного до нагружения, определялся максимальный коэффициент взаимной корреляции двух сравниваемых спектров и величина смещения по частоте, при котором наблюдается максимальный коэффициент корреляции. Максимальный коэффициент корреляции дает информацию об изменении формы спектра сигнала, регистрируе- 

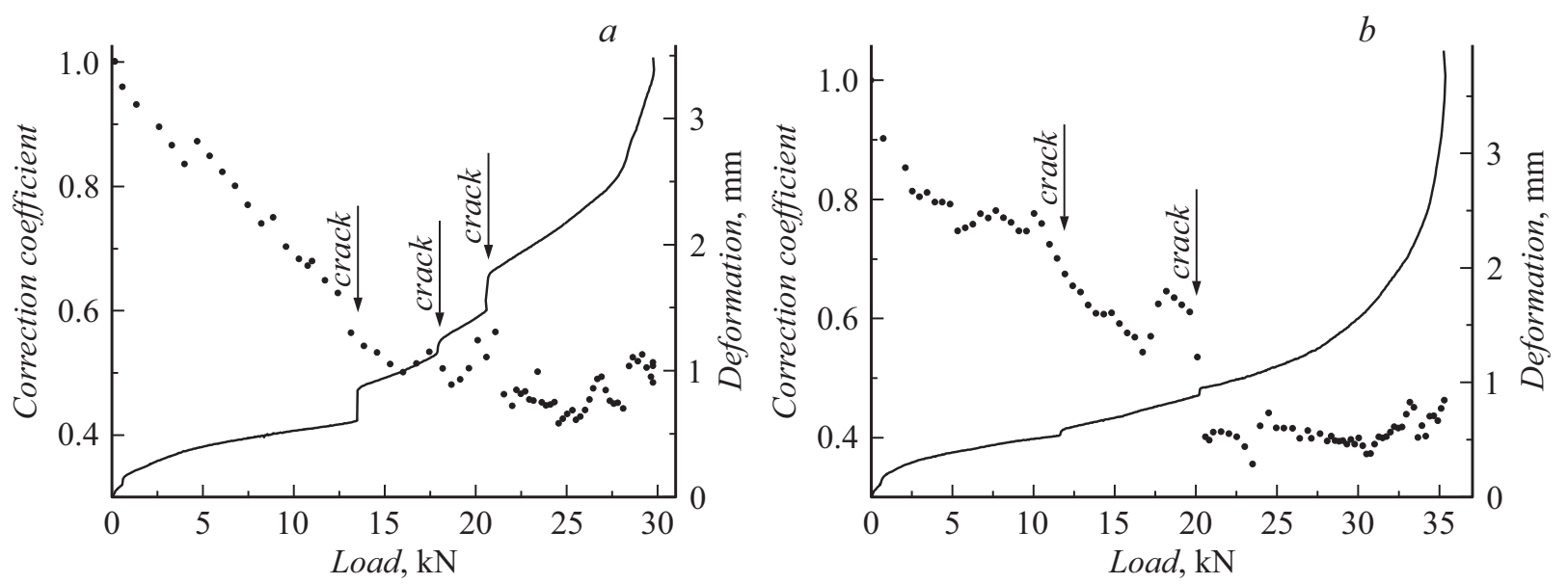

Рис. 4. Изменение максимального коэффициента корреляции спектра сигнала в процессе изгиба бетонных балок, армированных стеклопластиковой $(a)$ и стальной $(b)$ арматурой.
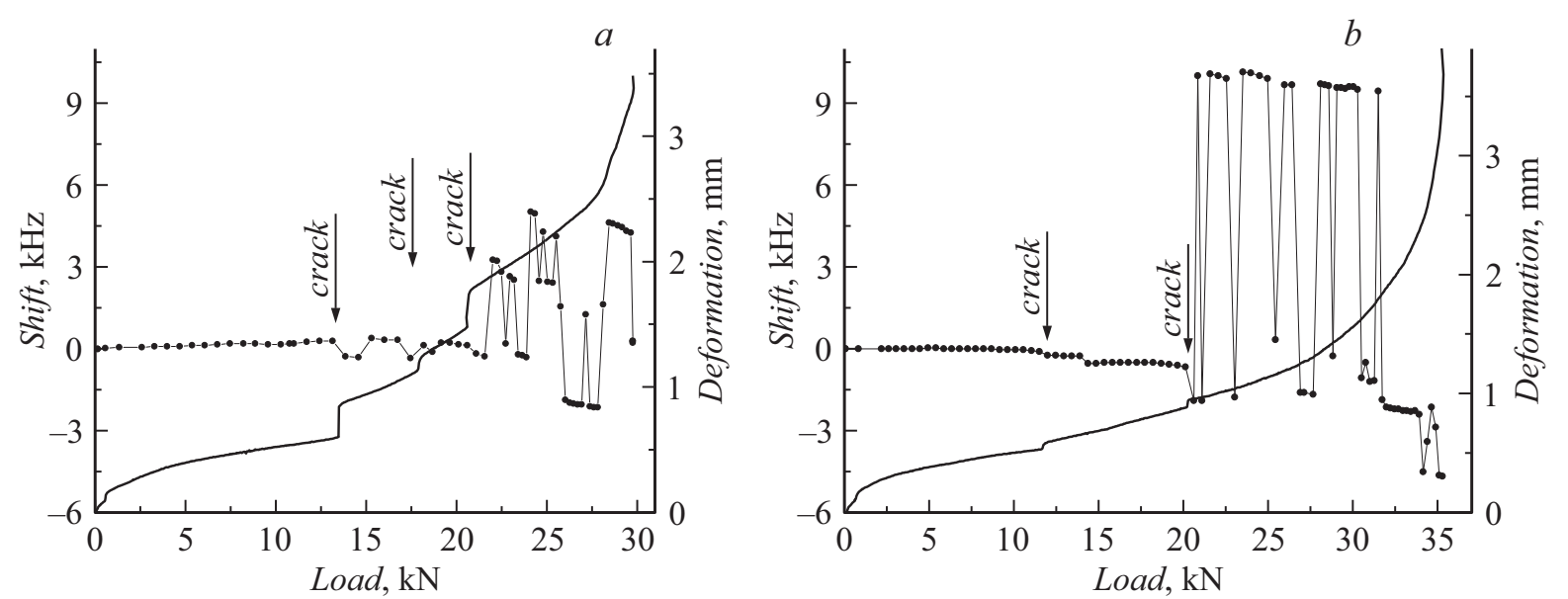

Рис. 5. Изменение смещения по частоте, при котором наблюдается максимальный коэффициент корреляции, в процессе изгиба бетонных балок, армированных стеклопластиковой $(a)$ и стальной $(b)$ арматурой.

мого в процессе возрастания внешней нагрузки. Смещение по частоте, при котором наблюдается максимальный коэффициент корреляции, позволяет оценить смещение спектра сигнала в сторону высоких или низких частот. На рис. 4 приведены зависимости максимального коэффициента корреляции, а на рис. 5 смещения для образцов армированного бетона в условиях изгиба.

Изменения спектрального состава электрического отклика происходит за счет появления дополнительных спектральных пиков при взаимодействии акустических волн возбуждения с образовавшимися трещинами. Наблюдается резкое уменьшение коэффициента корреляции в моменты скачкообразного прорастания трещин в зоне растяжения и изменения смещения, которые коррелируют с появлением или скачкообразным прорастанием трещин. При переходе в IV стадию нелинейной деформации, где происходит разрушение в бетоне сжатой зоны, наблюдается большое количество близких по величине спектральных пиков, соотношение между которыми меняется в процессе разрушения. В результате чего наблюдается скачкообразное изменение смещения то в сторону увеличения, то в сторону снижения и общее уменьшение коэффициента корреляции до 0.4-0.5. Эти два параметра могут быть использованы в качестве диагностических критериев для оценки процессов трещинообразования в условиях действия сжимающих нагрузок.

В результате проведения исследований установлено, что при используемой нами методике измерения (см. рис. 1) имеются особенности, связанные с геометрией расположения электрического и акустического датчиков относительно трещин, которые формируются в бетонной балке в процессе изгиба. В частности, на рис. 6 приведена фотография бетонной балки после разрушения в прессе.

При проведении испытаний для улучшения качества контакта подложки ударного устройства и акустического приемника производилось нанесение на поверхность испытываемого образца иммерсионного слоя из литола. Поэтому на рис. 7 явно видны отпечатки в местах расположения подложки $C$, по которой производится 


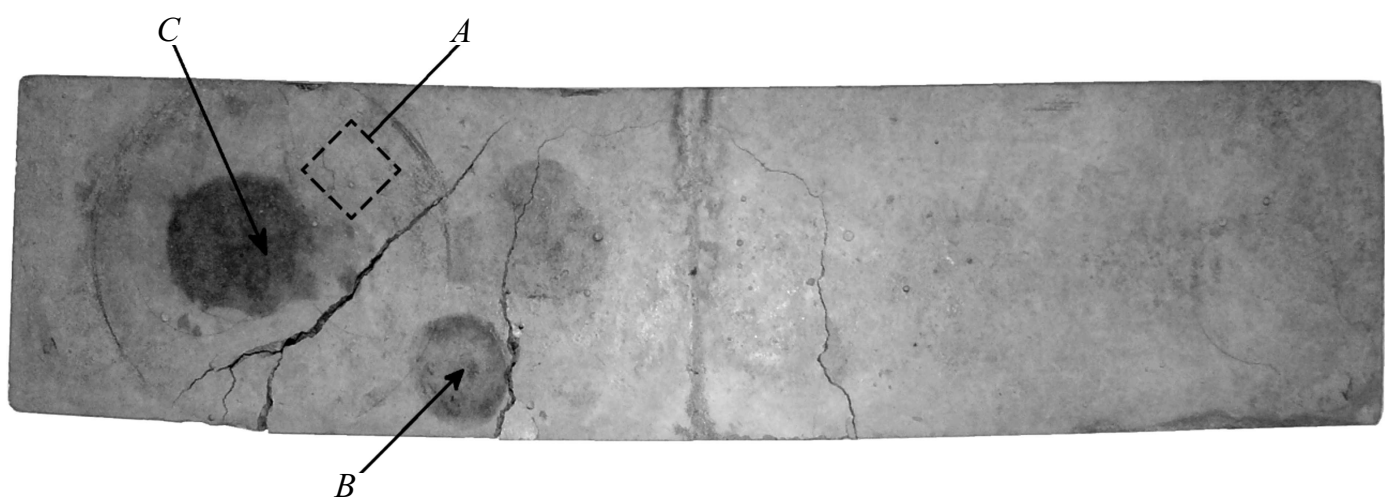

Рис. 6. Фотография бетонной балки, армированной стеклопластиковой арматурой, после проведения испытаний на изгиб.
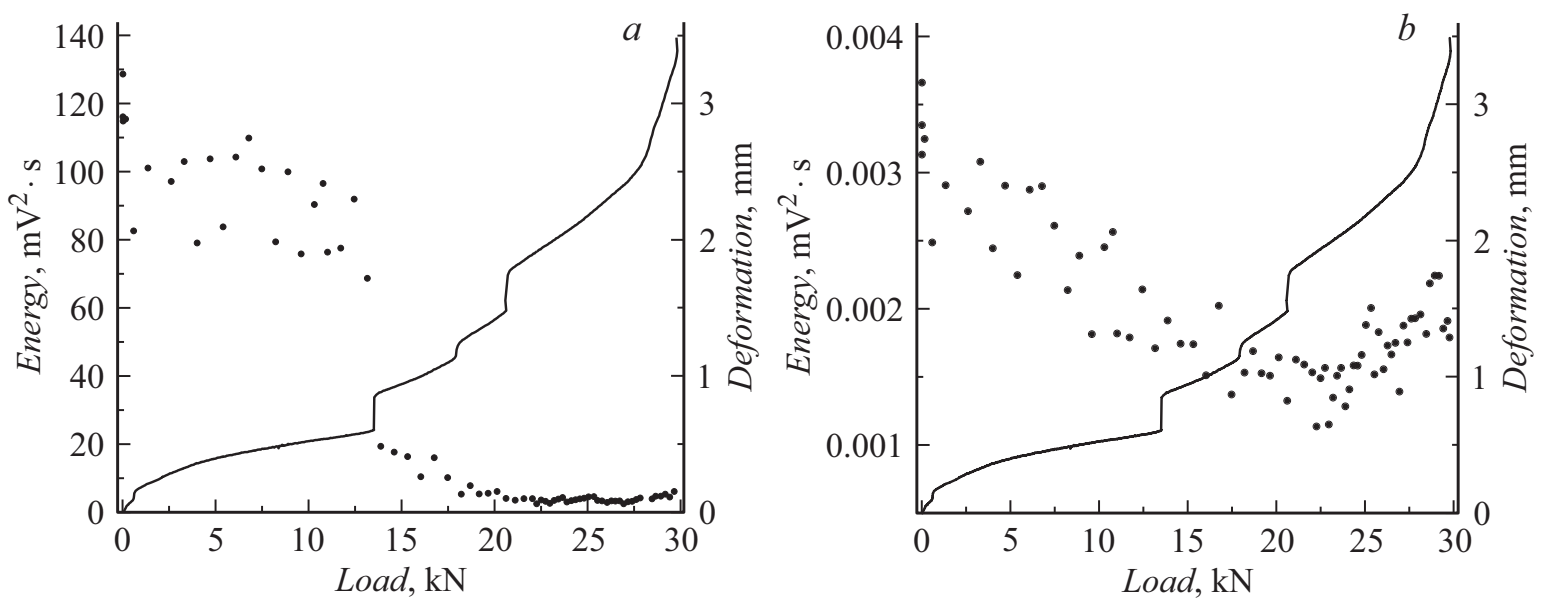

Рис. 7. Изменение энергии акустического $(a)$ и электрического $(b)$ сигналов в процессе нагружения армированной стеклопластиковой арматурой бетонной балки на четырехточечный изгиб.

удар бойком ударного устройства и акустического приемника $B$. Как видно из рисунка, в процессе разрушения происходит прорастание трещины между расположением электрического и акустического датчиков. Наличие такой трещины приводит к тому, что электрический $A$ и акустический $B$ датчики по разному располагаются относительно точки удара и трещины. В результате этого зависимости энергии акустического и электрического сигналов имеют существенные различия (см. рис. 7).

Как видно из рис. 7, зависимости энергии электрических и акустических сигналов хорошо коррелируют с геометрией расположения датчиков и характером разрушения армированной бетонной балки. После того как произошло появление макротрещины в растянутой зоне (при нагрузке $13.5 \mathrm{kN}$ ) резко (в 3.5 раза) уменьшилась энергия акустического сигнала. Это свидетельствует о том, что трещина прошла через всю толщу образца и акустическая волна, возникающая при ударном воздействии, практически полностью отразилась от этой трещины и не дошла до места расположения акустического приемника $B$. Наряду с этим электрический сигнал на всем протяжении от начала нагружения и до нагрузки $22 \mathrm{kN}$ уменьшается практически по линейной зависимости. Уменьшение энергии электрических откликов происходит в результате того, что пьезоэлектрические источники электрического отклика (кварцевые включения) зажимаются возникающими внутренними напряжениями в условиях постепенно возрастающей внешней нагрузки. Наблюдающееся после $22 \mathrm{kN}$ возрастание энергии электрических откликов может происходить за счет вклада в результирующий отклик отраженных от сквозной трещины волн. Таким образом, по характеру трансформации энергии электрических и акустических откликов можно судить о геометрии прорастания трещин.

В процессе изгиба напряжения в различных областях (местах) бетонной балки могут достигать разрушающих напряжений на растяжение или сжатие, и начинается процесс трещинообразования. При ударе по поверхности трехмерного образца продольная волна распространяется в образец по полусферическому волновому фронту и отражается от дефектов, неоднородностей и шести внешних границ образца. В результате в образце формируется сложная волновая картина, которая определяется геометрией образца, его упругими характеристиками, длительностью удара и наличием дефек- 

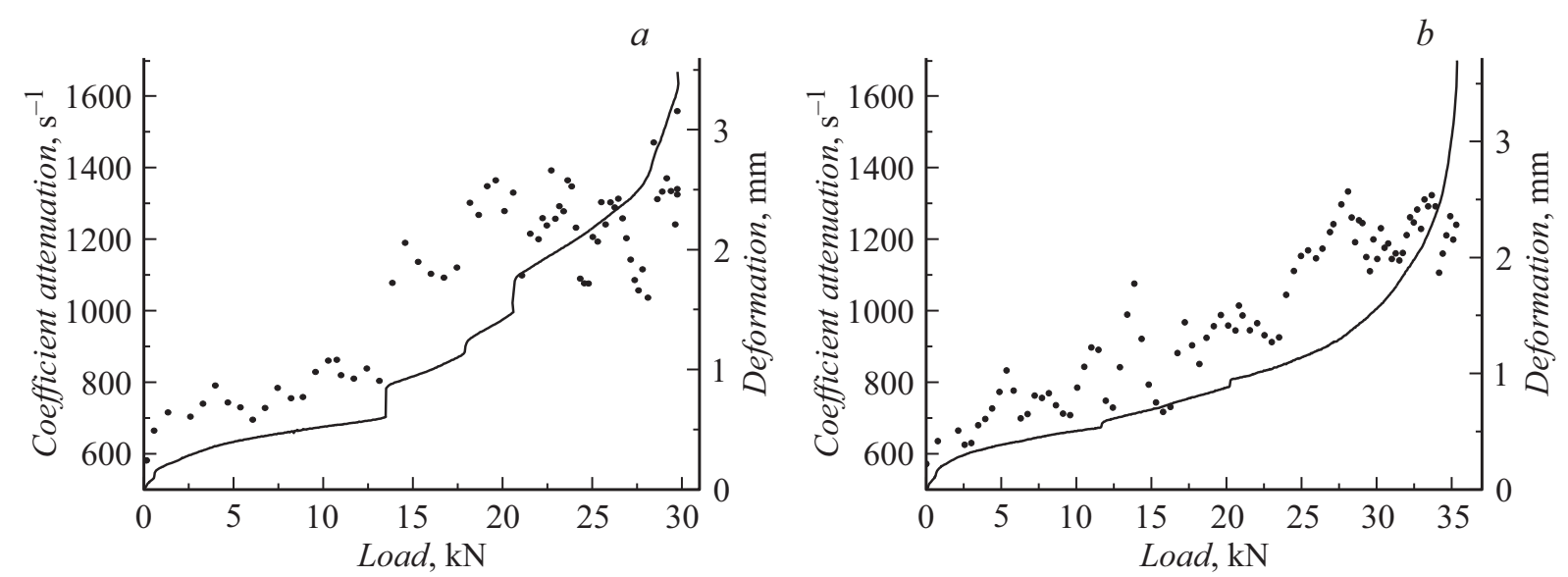

Рис. 8. Изменение коэффициента затухания энергии электрических откликов из балок, армированных стеклопластиковой $(a)$ и стальной $(b)$ арматурой в условиях испытания на изгиб.

тов $[10,22]$. Многократное рассеяние акустических волн на неоднородностях и дефектах приводит к затуханию энергии акустического возбуждения, а следовательно, и электрического отклика. Рассеяние упругих волн на трещинах отражает процесс затухания от времени. Для определения коэффициента затухания энергии сигнала из бетонных балок в зависимости от величины внешней нагрузки использован частотно-временной анализ, как это описано в работе [14]. Такая методика позволяет отслеживать затухание энергии сигнала как функцию времени в области любого, выбранного диапазона частот. В данном случае для анализа был выбран частотный диапазон от 2 до $40 \mathrm{kHz}$, в котором находится основная доля энергии электрических сигналов, возникающих в образцах при упругом ударном воздействии. На рис. 8 приведены графики, которые иллюстрируют зависимость коэффициента затухания энергии электрических откликов от величины внешней механической нагрузки. На рисунках зависимость коэффициента затухания от нагрузки наложена на нагрузочную кривую деформация-нагрузка, что позволяет совместить моменты появления макротрещин и этапы напряженно-деформированного состояния с характером изменения коэффициента затухания.

В поведении бетона, армированного различными типами арматуры, наблюдаются общие закономерности и отличительные особенности. В частности, для обоих типов арматуры наблюдается возрастание коэффициента затухания энергии электрических откликов от начала нагружения до полного разрушения. Однако для бетона, армированного стальной арматурой, общее возрастание происходит в 2 раза, в то время как для бетона, армированного стеклопластиковой арматурой, в 2.5 раза. Кроме того, при переходе во II стадию наблюдается резкое возрастание коэффициента затухания для бетона, армированного стеклопластиковой арматурой, а для бетона, армированного стальной арматурой, происходит плавное возрастание коэффициента затухания. Отличия в разрушении бетона, армированного стальной и стеклопластиковой арматурой заключаются в том, что после образования трещин пластиковая арматура за счет меньшего модуля упругости прогибается сильнее. В результате чего процессы прорастания трещин в бетоне со стеклопластиковой арматурой протекают более интенсивно, что приводит к тому, что и коэффициент затухания энергии электрических откликов в бетоне со стеклопластиковой арматурой в процессе нагружения растет быстрее. В процессе разрушения армированных бетонных балок на втором этапе возникают и прорастают трещины в нижней растянутой зоне балок. Эти трещины проходят через все сечение балки $(100 \mathrm{~mm})$ и имеют большое раскрытие и глубину. Размер этих трещин наиболее близко соответствует длине волны акустического возбуждения при ударном воздействии. Отражающие и рассеивающие свойства неоднородностей определяются размером неоднородности и отношением длины волны возбуждения к эффективному диаметру рассеивателя. В диапазоне частот от 2 до $40 \mathrm{kHz}$ минимальная длина волны $(\lambda)$ составляет $100 \mathrm{~mm}$. Поэтому наиболее интенсивное рассеяние должно происходить на макротрещинах, которые образуются при изгибе в бетоне растянутой зоны.

\section{Заключение}

В настоящей работе проведено исследование закономерностей изменения напряженно-деформированного состояния армированного стальной и стеклопластиковой арматурой бетона при изгибе и поиск диагностических критериев контроля разрушения армированного бетона на основе регистрации и анализе параметров электрического отклика на ударное воздействие.

Следующие заключительные выводы могут быть сделаны из экспериментального исследования.

Установлено, что нагрузочная зависимость в условиях изгиба для армированных бетонных балок имеет четыре характерных этапа. Начальный этап связан с процессами уплотнения поверхностного слоя образца, затем 
идет этап квазиупругой деформации, потом следует этап хрупкого разрушения бетона в зоне растяжения и заключительный этап, связанный с процессами разрушения на границе бетона с арматурой и разрушении бетона в сжатой зоне. Поведение бетонных балок, армированных стальной и стеклопластиковой арматурой, практически идентично, что дает основание предлагать для использования в условиях изгиба как стальную, так и стеклопластиковую арматуру.

Диагностическими признаками предстоящего разрушения армированного бетона является:

- возрастание в 2-2.5 раза коэффициента затухания энергии электрических откликов;

- уширение спектра электрического отклика как в сторону высоких, так и низких частот;

- уменьшение энергии электрических откликов в 2 раза;

- уменьшение максимального коэффициента взаимной корреляции анализируемых спектров сигналов с исходным спектром до 0.4-0.45;

- скачкообразное частотное смещение, при котором наблюдается максимальный коэффициент взаимной корреляции спектров сигналов, регистрируемых на различных этапах нагружения, с исходным спектром до нагружения.

Результаты экспериментов показали, что предложенный метод имеет потенциал для мониторинга эволюции повреждений в бетоне при изгибе.

Работа выполнена при поддержке Российского научного фонда (грант № 16-19-10119).

\section{Список литературы}

[1] Pendhari S.S., Kant T., Desai Y.M. // Compos. Struct. 2008. Vol. 84. P. 114-124.

[2] Gribniak V., Kaklauskas G., Torres L., Daniunas A., Timinskas E., Gudonis E. // Compos. Part B Eng. 2013. Vol. 50. P. 158-170.

[3] Paegle I., Minelli F., Fischer G. // Cement Concrete Composites. 2016. Vol. 73. P. 147-163.

[4] Yan F., Lin Z., Yang M. // Compos. Part B Eng. 2016. Vol. 98. P. 56-69.

[5] Aggelis D.G., Soulioti D.V., Sapouridis N., Barkoula N.M., Paipetis A.S., Matikas T.E. // Construction Building Materials. 2011. Vol. 25. N 11. P. 4126-4131.

[6] Alam S.Y., Loukili A. // Intern. J. Fracture. 2017. Vol. 206. N 1. P. 49-66.

[7] Kyriazopoulos A., Anastasiadis C., Triantis D., Brown C.J. // Constr. Build. Mater. 2011. Vol. 29. P. 1980-1990.

[8] Alexandridis A., Triantis D., Stavrakas I., Stergiopoulos C. // Constr. Build. Mater. 2012. Vol. 30. P. 294-300.

[9] Gade S.O., Alaca B.B., Sause M.G.R. // J. Nondestructive Evaluation. 2017. Vol. 36. P. 21.

[10] Hsiao C., Cheng C.-C., Liou T., Juang Y. // NDT\& E Int. 2008. Vol. 41. P. 98-107.

[11] Krzemień K., Hager I. // Constr. Build. Mater. 2015. Vol. 96. P. $155-163$.

[12] Song H., Popovics J.S. // Cement and Concrete Composites. 2017. Vol. 83. P. $111-124$
[13] In C.-W., Schempp F., Kim J.-Y., Jacobs L.J. // J. Nondestructive Evaluation. 2015. Vol. 34. P. 272.

14] Quiviger A., Payan C., Chaix J.-F., Garnier V., Salin J. // NDT \& E Int. 2012. Vol. 45. P. 128-132.

[15] Махмудов Х.Ф., Менжулин М.Г., Захарян М.В., Султонов У., Абдурахманов 3.М. // ЖТФ. 2015. Т. 85. Вып. 11. C. 79-85. [Makhmudov Kh.F., Menzhulinb M.G., Zakharyanb M.V., Sultonovc U., Abdurakhmanovc Z.M. // Techn. Phys. 2015. Vol. 60. N 11. P. 1651-1657.]

[16] Fengqi G., Zhiwu Y., Peng L., Zhi D. // Res. Nondestr. Eval. 2015. Vol. 27. N 1. P. 26-33.

[17] Seppänen A., Hallaji M., Pour-Ghaz M. // Struct. Health. Monit. 2017. Vol. 16. N 2. P. 215-224.

[18] Fursa T.V., Dann D.D., Petrov M.V. // Constr. Build. Mater. 2017. Vol. 155. P. 451-462.

[19] Fursa T.V., Dann D.D., Petrov M.V., Lykov A.E. // J. Nondestruct. Eval. 2017. Vol. 36. Is. 2. N 30.

[20] Фурса Т.В., Уи,ын Г.Е., Данн Д.Д., Петров М.В. // Дефектоскопия. 2017. № 2. С. 24-30. [Fursa T.V., Utsyn G.E., Dann D.D., Petrov M.V. // Russian J. Nondestructive Testing. 2017. Vol. 53. N 2. P. 104-110.]

[21] Суржиков В.П., Федотов П.И., Хорсов Н.Н. // ЖТФ. 2015. Т. 85. Вып. 3. С. 69-72. [Surzhikov V.P., Fedotov P.I., Khorsov N.N. // Techn. Phys. 2015. Vol. 60. N 3. P. 385-388.]

[22] Lin Y., Sansalone M. // J. Acoust. Soc. Am. 1992. Vol. 91. N 2. P. $885-893$. 